\title{
O MOVIMENTO DE ACESSO ABERTO E A UFBA: DEZ ANOS DE IMPLANTAÇÃO DO REPOSITÓRIO INSTITUCIONAL
}

\begin{abstract}
Resumo: Este artigo visa homenagear e divulgar os dez anos de implantação do Repositório Institucional da Universidade Federal da Bahia, completados em 2020, bem como mapear as produções acadêmicas e científicas realizadas sobre o repositório, seja como objeto de estudo ou como fonte de informação na realização de diversas pesquisas. Com uma abordagem qualitativa e quantitativa, o levantamento possui natureza descritiva, no qual procura descrever o Movimento de Acesso Aberto no cenário internacional, até a sua chegada ao Brasil pelo Manifesto de acesso livre à informação, promovido pelo Instituto Brasileiro de Informação em Ciência e Tecnologia, em 2005. A implantação do repositório foi fruto dos estudos da Doutora Flávia Rosa entre os anos de 2008 e 2010, com defesa de tese em 2011. O presente levantamento revela que o repositório tem se consolidado como uma importante fonte de informação para a produção de dissertações e artigos científicos, assim como tem sido objeto de estudo para diversos pesquisadores. Nesses dez anos de existência, o repositório conta com mais de 30 mil trabalhos disponibilizados em acesso aberto, com potencial para alavancar a visibilidade das pesquisas, dos pesquisadores e da instituição.
\end{abstract}

Davilene Souza Santos

Mestra em Estudos

Interdisciplinares sobre a Universidade pela Universidade

Federal da Bahia

(PPGEISU/UFBA)

davilenes13@gmail.com

Flávia Rosa

Doutora em Cultura e Sociedade pela Faculdade de Comunicação da Universidade Federal da

Bahia (Facom/UFBA)

fflaviagoulartroza@gmail.com

Palavras-chave: Movimento de Acesso Aberto. Repositório Institucional. Universidade Federal da Bahia.

\section{THE OPEN ACCESS MOVEMENT AND UFBA: TEN YEARS OF IMPLEMENTATION OF THE INSTITUTIONAL REPOSITORY}

\begin{abstract}
This article aims to honor and publicize the ten years of implementation of the Institutional Repository of the Federal University of Bahia, completed in 2020, as well as to map the academic and scientific productions carried out on the repository, either as an object of study or as a source of information in the realization of several surveys. With a qualitative and quantitative approach, the survey has a descriptive nature, in which it seeks to describe the Open Access Movement in the international scenario, until its arrival in Brazil by the Manifest of free access to information, promoted by the Brazilian Institute of Information in Science and Technology , in 2005. The implantation of the repository was the result of the studies of Dr. Flávia Rosa between the years 2008 and 2010, with the defense of a thesis in 2011. The present survey reveals that the repository has consolidated itself as an important source of information for the production of dissertations and scientific articles, as well as has been the object of study for several researchers. In these ten years of existence, the repository has more than 30 thousand works made available in open access, with the potential to leverage the visibility of research, researchers and the institution.
\end{abstract}

Keywords: Open Access Movement. Institutional Repository. Federal University of Bahia. 


\section{INTRODUÇÃO}

A pesquisa científica visa à ampliação do conhecimento acerca de um tema, de um fenômeno ou um acontecimento histórico, possibilitando a compreensão de aspectos envolvidos em uma sociedade. Comunicar os estudos realizados sobre determinado assunto tem se tornado a tônica da vida acadêmica contemporânea. A velocidade com que as informações são disponibilizadas atualmente encontra nas Tecnologias de Informação e Comunicação (TIC), em particular a internet, o aparato necessário para a ampliação do acesso à informação.

Comunicar de forma rápida e com qualidade os resultados de pesquisas científicas permite que o conhecimento seja recebido por outros pesquisadores interessados no tema, e com isso possa gerar maiores argumentações, refutações e aprimoramento do tema proposto. Para Meadows (1999, p. vii) “[...] A comunicação eficiente e eficaz constitui parte essencial do processo de investigação científica”.

Produzir conhecimento científico e comunicá-lo de forma ampla e irrestrita torna-se primordial em tempos de avanços tecnológicos e de escassez de recursos. Para Targino (1998, p. 46), “A comunicação científica é indispensável à atividade científica, pois permite somar esforços individuais dos membros das comunidades científicas". É nessa perspectiva que emerge a necessidade da comunicação mais efetiva e célere entre os membros de uma comunidade científica.

Os estudos produzidos por pesquisadores de diversas áreas, além de gerar conhecimento, visam oportunizar um debate diante do tema pesquisado. Para que esse debate ocorra, as pesquisas precisam circular, chegar até o receptor da informação, e de forma ágil. As revistas científicas foram adotadas como o canal de comunicação viável e eficiente para tal finalidade. No entanto, esse meio de comunicação tornou-se oneroso ao longo do tempo, e as assinaturas das revistas científicas, contratadas pelas instituições de ensino superior e de pesquisas tornaram-se caras e supervalorizadas.

Diante da insatisfação dos pesquisadores e das instituições, outras iniciativas outras de disseminação da produção acadêmica e científica foram adotadas, e na década de 1990 um pesquisador norte-americano propôs a criação de um repositório de pesquisas em acesso 
aberto, no qual os estudiosos das áreas de Física, Matemática e Computação pudessem socializar as pesquisas realizadas, e dessa forma construir uma rede de comunicação científica sem interferência das grandes editoras de revistas científicas. Nesse sentido, Alvarez e Caregnato (2017, p. 105) acrescentam que:

A produção, disseminação e uso da informação são fundamentais para o desenvolvimento das comunidades científicas. Desde séculos passados, o ato de comunicar através de canais informais e formais se tornou um fato necessário para a construção de novo conhecimento.

Foi na cidade de Los Alamos que o pesquisador Paul Ginsparg criou o repositório de acesso aberto denominado ArXiv, em atividade até os dias atuais. No estudo de Alvarez e Caregnato (2017, p. 110), que versa sobre a atuação do repositório ArXiv entre os anos de 2010-2015, os autores retomam as especificações deste repositório e discorrem que: “O ArXiv é um repositório temático especializado em preprints de acesso aberto. As áreas abrangidas incluem Física, Matemática, Ciências a Computação, Ciências não-lineares, Biologia Quantitativa e Estatística”.

Os autores também definem que "[...] preprints são documentos digitais que foram submetidos a um repositório sem revisão por pares". (ALVAREZ; CAREGNATO, 2017, p. 107). Retomando ao ArXiv, este se tornou um marco na criação dos repositórios de acesso aberto, mas o debate permanecia em torno da temática e da disponibilização das pesquisas científicas de forma ampla, irrestrita e gratuita.

Foi por meio de convenções realizadas em vários países, tanto da Europa como do continente americano, que se formulou uma estratégia de comunicação científica em acesso aberto, que motiva a mobilização por parte de diversas instituições de ensino e pesquisa a romper parcialmente com as revistas científicas comerciais, de modo que as comunicações de pesquisas realizadas possam ser disponibilizadas em repositórios temáticos ou institucionais, como também por meio de periódicos de acesso aberto.

Ao tratarmos do Movimento de Acesso Aberto (MAA), iniciado por meio de convenções realizadas no cenário internacional, destacamos também a importância do Instituto Brasileiro de Informação em Ciência e Tecnologia (Ibict) na promoção desse movimento, e como a Universidade Federal da Bahia (UFBA) se insere nesse contexto. 
Na seção que aborda a implantação do repositório institucional da UFBA, tema central desse artigo, relatam-se as configurações e o contexto que permitiram a inserção da UFBA no MAA, e como este vem se desenvolvendo em termos de quantitativo de documentos disponibilizados, assim como os estudos realizados tendo-o como objeto de pesquisa ou mesmo como base para fonte de informações, contribuindo dessa forma para ampliar os estudos efetivados por discentes e docentes de diversas instituições.

\section{O MOVIMENTO DE ACESSO ABERTO}

O MAA nasce da motivação de pesquisadores de diversas áreas do conhecimento em obter estratégias que minimizem os custos com a publicação de estudos científicos. As instituições de pesquisas, que subsidiavam os pesquisadores com insumos para a execução das investigações, viam-se pressionadas pelas editoras dos periódicos científicos, que ao identificar um nicho promissor e rentável, oneravam os custos de aquisição das revistas científica, necessárias à comunicação das pesquisas em curso.

Como forma de debaterem a situação de momento, convenções como a de Santa Fé no Novo México (EUA), em 1999, e as convenções de Budapeste e de Berlim, em 2002, foram realizadas. Em virtude dessas convenções, criou-se a Budapeste Open Access Initiative (BOAI), ${ }^{1}$ conforme relatam Silva e Alcará (2009, p. 101):

\footnotetext{
Foi criada em fevereiro de 2002, a partir da reunião promovida pelo Open Society Institute (OSI), da Soro Fundation, com o propósito de analisar como as iniciativas isoladas poderiam trabalhar conjuntamente e como o OSI e as demais fundações poderiam utilizar de forma mais efetiva seus recursos para contribuir com o acesso aberto.
}

A respeito da nomenclatura Open Access, Costa e Leite (2016, p. 4) informam que "a expressão Open Access (OA) foi utilizada pela primeira vez para este propósito pela BOAI'. Ademais, a convenção de Budapeste tornou-se um marco para o MAA, visto que dela tivemos como resultado a declaração que subsidia as ações que promoveram o acesso aberto, a

\footnotetext{
${ }^{1}$ Disponível em: https://translate.google.com.br/translate?hl=pt-

$\mathrm{BR} \& \mathrm{sl}=\mathrm{en} \& \mathrm{tl}=\mathrm{pt} \& \mathrm{u}=\mathrm{https} \% 3 \mathrm{~A} \% 2 \mathrm{~F} \% 2 \mathrm{Fwww}$. budapestopenaccessinitiative.org\%2Fread. Acesso em: 14 out. 2018.
} 
exemplo das estratégias que deverão ser adotadas para o desenvolvimento da comunicação científica em Open Access.

As estratégias orientadas pela Declaração de Budapeste permeiam tanto o cenário das Instituições de Ensino Superior (IES), como também das instituições de pesquisa, ao admitir a implantação de repositórios institucionais ou temáticos, respectivamente, além da criação de periódicos científicos de acesso aberto, ou seja, a disponibilização de conteúdo científico sem custo para o pesquisador e para o leitor. Essas estratégias foram denominadas como via verde e via dourada, em que a via verde simboliza a criação dos repositórios institucionais e a via dourada representada pelos periódicos científicos de acesso aberto. Nesse sentido, Kuramoto (2015, p. 12) acrescenta que,

[...] os repositórios fornecem um elemento importante na reforma do sistema de trabalhos acadêmicos, comunicando e expandindo o acesso à pesquisa, além de reafirmar o controle sobre as pesquisas pela academia, proporcionando maior relevância agregada às instituições e bibliotecas que os apoiam.

No Brasil, o MAA se apresenta através do Ibict, que atua como um importante vetor de divulgação desse movimento e promove inúmeras ações que visam maximizar os ideais propostos por este na esfera internacional. Ao se lançar como um dos incentivadores do MAA no Brasil, o Ibict lança, no ano de 2005, o Manifesto Brasileiro de Apoio ao Acesso Livre à Informação Científica ${ }^{2}$, e posteriormente, em 2016, amplia o movimento e lança Manifesto de Acesso Aberto a Dados da Pesquisa Brasileira para Ciência Cidadã. ${ }^{3}$

Nesse cenário de incentivo ao acesso aberto, o Ibict lançou, em 2009, juntamente com Financiadora de Estudos e Projetos (Finep), o edital FINEP/PCAL XBDB 002/2009. (KURAMOTO, 2009). Esse edital selecionou instituições para que participassem de um projeto piloto para implantação de repositório institucional. Dentre as instituições selecionadas, temos a UFBA com um projeto elaborado por uma equipe multidisciplinar que atua conjuntamente para concretizar a disseminação do conhecimento na Universidade de forma ampla e democrática. A respeito da importância da implantação de um repositório institucional, Kuramoto (2015, p. 12) acrescenta que:

\footnotetext{
${ }^{2}$ Disponível em: http://livroaberto.ibict.br/Manifesto.pdf. Acesso em: 30 abr. 2020.

${ }^{3}$ Disponível em: http://www.ibict.br/sala-de-imprensa/noticias/item/478-ibict-lanca-manifesto-de-acesso-abertoa-dados-da-pesquisa-brasileira-para-ciencia-cidada. Acesso em: 30 abr. 2020.
} 
Os repositórios têm o potencial de servir como indicadores tangíveis da qualidade de uma instituição, demonstrando a relevância científica, social e econômica de suas atividades de pesquisa, aumentando assim a visibilidade da instituição, o seu status e o seu valor público.

É nesse cenário e com essa perspectiva que a UFBA se insere no MAA, de modo que possa contribuir com a disseminação do conhecimento produzido pela instituição de forma ampla, irrestrita, gratuita e democrática. Essa busca pela democratização do acesso e disseminação da informação que diversas comunidades científicas produzem na UFBA é tema do estudo realizados pela doutora Flávia Rosa (2011) entre os anos de 2008-2010, e que contribuiu para a implantação do repositório da UFBA em 2010.

\section{A IMPLANTAÇÃO DO REPOSITÓRIO INSTITUCIONAL DA UFBA}

A inserção da UFBA no MAA ocorre de modo significativo, com pesquisas desenvolvidas desde a primeira década dos anos 2000, com o intuito de promover a disseminação do conhecimento produzido pela instituição de forma ampla, aumentando a visibilidade da UFBA no cenário local, nacional e internacional. A criação de um repositório seria um importante propulsor para o avanço da universidade em direção a disponibilização da produção acadêmica em acesso aberto. Segundo Costa (2018, p. 28) "repositórios são instrumentos utilizados para compartilhamento das informações científicas, [...] geradas no âmbito de uma instituição de pesquisa ou universidade sejam armazenados, recuperados e baixados por todos os interessados sem barreira de pagamento e reuso".

Nesse sentido, a aprovação na seleção do edital publicado pelo Ibict e Finep em 2009 possibilitou à instituição o recebimento de um kit tecnológico, com um servidor dedicado para o repositório em implantação e assim possibilitou a criação do repositório. A respeito disso, Rosa (2011, p. 201) acrescenta que, "Com o Edital, deu-se o primeiro passo na implantação de ações contemplando o acesso aberto à produção científica das unidades de pesquisa. As instituições contempladas nesse Edital receberiam um servidor, já com o DSpace instalado".

O DSpace é um software livre destinado a implementação do Open Acess. De acordo com Meirelles (2009, p. 57), foi “desenvolvido para possibilitar a criação de bibliotecas digitais e repositórios institucionais ou temáticos, com funções de captura, distribuição e 
preservação da produção intelectual institucional". Dentre as suas principais característica, Meirelles (2009, p. 57, grifo do autor) inclui:

\begin{abstract}
A utilização de arquitetura de software simples e eficiente, workflow, indexação para navegação e busca entre coleções e comunidades, recuperação em diferentes formatos. Utiliza modelo de preservação digital Open Archival Information System $(O A I S)$, intencionalmente implementado para servir de repositório institucional, dentro do padrão Dublin Core, e direcionado para o acesso aberto à informação científica.
\end{abstract}

Nesse contexto, o Repositório Institucional da Universidade Federal da Bahia (RIUFBA) tem a sua institucionalização no ano de 2010, através da Portaria $n^{\circ}$ 024/2010 publicada pelo Gabinete da Reitoria, assinada pelo então reitor professor Naomar Monteiro de Almeida Filho, em 7 de janeiro 2010. Por outro lado, através da Portaria n ${ }^{\circ}$. 125/2015 constituiu-se um grupo gestor da Política do Repositório Institucional, responsável pelo desenvolvimento e manutenção deste, vinculado à Reitoria da instituição, composta por membros de diversos setores da instituição, tais como: Pró-Reitoria de Pesquisa, Criação e Inovação na Presidência; Instituto de Ciência da Informação; Editora Universitária; Superintendência do Sistema de Bibliotecas; Superintendência de Tecnologia da Informação. Posteriormente, a presidência do grupo gestor passou a ter como responsável a Superintendência do Sistema de Bibliotecas, até os dias atuais.

Uma das primeiras coleções a serem incorporadas no RI-UFBA foram as obras publicadas pela Editora Universitária da UFBA (Edufba), com as devidas anuências dos autores. De acordo com Rosa (2011), para a inserção de documentos no RI-UFBA, nessa fase inicial, houve a contratação de um gestor, que coordenou as ações de povoamento das comunidades atribuídas às mais diversas instâncias da Universidade, desde a Reitoria, perpassando pela Editora e chegando às unidades acadêmicas e seus cursos de graduação e programas de pós-graduação.

Nessa primeira década de implantação do RI-UFBA, percebe-se um crescimento significativo na disponibilização de documentos. Atendendo ao que propõe o MAA, a disponibilização de conteúdo pode ocorrer tanto por autoarquivamento - quando realizada

\footnotetext{
${ }^{4}$ Disponível em: https://repositorio.ufba.br/ri/about/politica\%20institucional.pdf. Acesso em: 30 abr. 2020.

${ }^{5}$ Disponível em: https://repositorio.ufba.br/ri/about/Portaria_n125.pdf. Acesso em: 30 abr. 2020.
} 
pelo autor da produção científica ou acadêmica, quanto pela inserção por terceiros, tais como: secretários (as) de Programas de Pós-Graduação, bibliotecários ou colaboradores destinados a essa finalidade, de modo que possam subsidiar o acervo inicial dos repositórios. Nesse sentido, o autoarquivamento, que nas estratégias do MAA compõe a via verde, representada pelos repositórios, apresenta-se, de acordo com Triska e Café (2001, p. 93) como:

[...] o direito de o próprio autor enviar o seu texto para publicação sem intermédio de terceiros. Trata-se de um conceito inovador cujos objetivos são tornar o texto disponível o mais rápido possível e favorecer o acesso democrático e gratuito das publicações eletrônicas, enfraquecendo o monopólio das grandes editoras científicas que até recentemente detinham em seu poder os direitos de publicação.

Na fase inicial de implantação esperava-se, segundo Rosa (2011), a inserção de 6.000 documentos no RI-UFBA. Em levantamento recente, Santos e Rosa (2020) identificaram que em média a inserção da produção acadêmica e científica no repositório gira em torno de 3.000 documentos disponibilizados anualmente.

Esse dado foi percebido em três verificações realizadas entre os anos de 2018 e 2019, constatando que o quantitativo de documentos havia saltado de 22 mil documentos no início de 2018, para aproximadamente 27.900 no final de 2019. Mais recentemente, em abril de 2020, constata-se que o RI-UFBA já conta com mais de 30.000 documentos inseridos. Essas informações revelam que de fato há um crescimento médio de 3.000 documentos por ano, disponibilizados no repositório da UFBA.

A partir desse crescimento expressivo que avistamos no RI-UFBA, nesse momento significativo em que se completa uma década desde a sua implantação, cabe-nos verificar na literatura científica, o que tem sido produzido acerca desse importante instrumento de disseminação do conhecimento, dentro e fora da instituição, pois este se enquadra no rol dos repositórios institucionais pesquisados por diversos estudiosos da área, a exemplo das menções realizadas a ele em estudos fora do Nordeste brasileiro.

\subsection{A produção científica e acadêmica sobre o RI-UFBA em uma década}

Na perspectiva de homenagear e ao mesmo tempo divulgar o RI-UFBA, em seu décimo aniversário de implantação, têm-se por objetivo mapear na literatura científica os estudos que 
foram realizados sobre o repositório da UFBA. Além disso, buscou-se levantar outros estudos já realizados acerca dos demais repositórios institucionais brasileiros, que citam de alguma forma e a título de exemplo o RI-UFBA, seja porque participou do edital Ibict/Finep, junto com outras instituições, ou porque possui um serviço de disseminação seletiva, denominado Alerta, pouco identificado em outros repositórios.

Outra categoria que identificamos com o mapeamento foi a menção ao RI-UFBA como um canal de comunicação científica, juntamente com outras bases de dados renomadas, para aquisição de dados e informações que subsidiassem pesquisas realizadas na graduação e na pós-graduação na UFBA, como parte do Trabalho de Conclusão de Curso (TCC) ou dissertação de Mestrado. Esse último dado revela que o RI-UFBA vem se consolidando junto à comunidade acadêmica como um instrumento de disseminação das pesquisas realizadas na Instituição, de modo a contribuir com diversos estudos dos membros da comunidade acadêmica.

Diante das características de disponibilização de conteúdo do RI-UFBA, que possui dentre as suas subcomunidades documentos de ordem administrativa, acadêmica e científica, que conta com tipos diversos de fontes de informação, tais como: dissertações e teses, livros, capítulos de livros, artigos de periódicos, artigos apresentados em eventos, atas de reunião, planos de desenvolvimento institucional, relatórios de pesquisa, pareceres, normas e procedimentos administrativos, regimentos internos dentre outros. Essas fontes de informação podem ser denominadas, conforme corrobora Cunha (2020), como fontes primária, secundária ou terciária.

Dessa forma, de fato os discentes em processo de produção acadêmica para finalização de curso, seja de graduação ou pós-graduação, encontram materiais diversos, que abrangem ramos diversificados, tanto por parte do conhecimento, como por parte da classificação de fontes de informação, o que enriquece a pesquisa em execução.

\section{PERCURSO METODOLÓGICO}

A metodologia adotada para o levantamento das informações que compõe a pesquisa se apresenta por meio da busca bibliográfica em bases de dados como a Biblioteca Digital de Teses e Dissertações (BDTD), Google Acadêmico, Portal de Periódicos da Coordenação de 
Aperfeiçoamento de Pessoal de Nível Superior (Capes) e o Repositório Institucional da UFBA. Por outro lado, a análise dos dados possui um caráter descritivo, que, de acordo com Gil (2008, p. 28), "tem como objetivo primordial a descrição das características de determinada população ou fenômeno". Já a abordagem adotada perpassa pela pesquisa qualiquantitativa.

Segundo Minayo (1992), a pesquisa qualitativa está centrada dentre outros aspectos no aprofundamento das relações, dos processos e dos fenômenos. No que tange a união de ambas as abordagens, Fonseca (2002, p. 20) ressalta que, "A utilização conjunta da pesquisa qualitativa e quantitativa permite recolher mais informações do que se poderia conseguir isoladamente". Nesse sentido, a união dessas abordagens permite nos beneficiarmos de um maior número de variáveis que descrevam o fenômeno da produção acadêmica e científica, em torno do tema central, o Repositório Institucional da UFBA.

A coleta dos dados foi realizada com estratégia de busca no próprio RI-UFBA, com os termos "repositórios, repositório institucional e RI-UFBA". A recuperação dos documentos nos permitiu filtrar somente aqueles que de fato mencionavam o RI-UFBA de alguma forma, dentre as já citadas no texto. Por outro lado, buscamos também no site de busca "Google Acadêmico" artigos, dissertações e tese que versassem tematicamente sobre o repositório institucional, e filtramos pelo título, pelo resumo e, posteriormente, por meio de uma leitura dinâmica, para identificar se o documento de fato mencionava o RI-UFBA, de qual forma e com qual intenção. Outra fonte de informação escolhida para coleta e recuperação de dados sobre o RI-UFBA foi o Portal Público do Sistema Integrado de Gestão de Atividades Acadêmicas (Sigaa) ${ }^{6}$ da UFBA, que permitiu identificar dissertações defendidas, mas que ainda não tinham sido inseridas no RI-UFBA. Com esse conjunto de estratégias adotadas, o resultado foi a identificação e recuperação de 44 documentos que abordavam o RI-UFBA em seu contexto de pesquisa.

\section{ANÁLISE E DISCUSSÃO DOS DADOS}

\footnotetext{
${ }^{6}$ Disponível em: https://sigaa.ufba.br/sigaa/public/programa/lista.jsf?aba=p-academico. Acesso em: 30 abr. 2020
} 
O levantamento possibilitou a recuperação de 48 documentos que possui o RI-UFBA como objeto de estudo ou mesmo como instrumento de fonte de referência, juntamente com outras bases de dados. As tipologias dos documentos recuperados são descritas na Tabela 1, assim como o quantitativo de documentos para cada uma dessas.

Tabela 1: Tipologia e quantitativo dos documentos

\begin{tabular}{c|c|c} 
Tipologia & $\begin{array}{c}\text { Quantitativo de } \\
\text { documentos }\end{array}$ & Percentual \\
\hline Tese & 01 & $2 \%$ \\
\hline Dissertações & 10 & $21 \%$ \\
\hline Trabalho de Conclusão de Curso (TCC) & 03 & $6,2 \%$ \\
\hline Documentos Administrativos & 03 & $6,2 \%$ \\
\hline Publicação em Periódico & 17 & $35,4 \%$ \\
\hline Publicação em eventos & 11 & $23 \%$ \\
\hline Capítulo de livros & 03 & $6,2 \%$ \\
\hline Total de documentos & 48 & $100 \%$ \\
\hline
\end{tabular}

Fonte: elaborado pela autora (2020).

$\mathrm{Na}$ análise dos dados relativos à tipologia dos documentos que versam sobre o RIUFBA, identificamos que o tipo de documento que se destaca são os artigos, seja com publicação em periódicos, com 17 artigos localizados que exploram o universo dos repositórios institucionais e que publicaram sobre o RI-UFBA, ou seja, através dos trabalhos publicados em eventos, que se apresentam com 11 documentos, perfazendo um total de 28 artigos que versam sobre o RI-UFBA.

Por essa razão, analisaremos na próxima categoria quais periódicos têm realizado essa comunicação científica a respeito do acesso aberto, assim como os eventos. É importante identificar quais revistas científicas e os eventos que estão engajados na disseminação do conhecimento a respeito do acesso aberto, através dos repositórios institucionais.

Ainda em relação a tipologias, a terceira com maior volume diz respeito às dissertações, trabalho final do curso de mestrado. Esse tipo de documento se apresenta com dez produções realizadas por discentes da UFBA. Interessante notar a diversificação dos programas de pós- 
graduação que trataram do tema Repositório institucional da UFBA. Cabe salientar que das dez dissertações recuperadas, quatro constam do Programa de Pós-Graduação em Ciência da Informação, três foram acolhidas pelo Programa de Pós-Graduação em Estudos Interdisciplinares sobre a Universidade, duas foram defendidas no Programa de PósGraduação em Ciência da Computação e uma no Programa de Pós-Graduação em Educação, todas aprovadas e comunicadas no RI-UFBA, ou no portal público do SIGAA, por enquanto.

Dando início às análises finais acerca das tipologias, notamos que três TCC foram produzidos tendo o RI-UFBA como tema ou como base de dados para obtenção de informação confiável a respeito do seu tema de pesquisa. Os cursos em que ocorrem esses trabalhos foram: Pedagogia, Medicina e Comunicação, nos anos 2011, 2013 e 2018, respectivamente.

A respeito de capítulos de livros, foram recuperados na ordem de documentos, publicados nos seguintes livros: Implantação e gestão de repositórios institucionais: políticas, memória, livre acesso e preservação, em 2009. Já em 2014 contamos com um capítulo na coleção CULT intitulado Enecult 10 anos. Por último, no ano de 2016, recuperamos um capítulo no livro intitulado Fronteiras e interfaces da comunicação científica.

Para de fato finalizarmos as análises, três documentos administrativos que trata do RIUFBA, o primeiro em 2010, que se trata da Portaria de implantação do RI, outro que diz respeito a uma ata de reunião realizada em 2011 do Conselho Universitário da Universidade Federal da Bahia e, por último, a Portaria de constituição do grupo gestor da Política do Repositório Institucional.

Analisaremos, portanto, quais periódicos e eventos têm difundido o acesso aberto, ao publicarem em suas revistas e anais de eventos textos que discorrem sobre o RI-UFBA. O periódico científico PontodeAcesso, do Instituto de Ciência da Informação da UFBA, publicou três artigos que têm como tema o RI-UFBA, dos 17 recuperados em periódicos. Esses artigos foram publicados nos anos de 2015, 2017 e 2019, um a cada dois anos. As demais revistas listadas na Tabela 2, apresentaram apenas uma publicação cada uma delas sobre o RI-UFBA.

Tabela 2: Periódicos com artigos publicados sobre o RI-UFBA 


\begin{tabular}{c|c} 
Periódicos & Quantitativo de Artigos \\
\hline PontodeAcesso & 03 \\
\hline Tendencia Editorial & 01 \\
\hline Pesquisa Brasileira em Ciência da Informação e \\
Biblioteconomia & 01 \\
\hline Perspectivas em Gestão \& Conhecimento & 01 \\
\hline Em Questão & 01 \\
\hline Revista Digital de Bibliotecon. Cienc. Inf. & 01 \\
\hline Cadernos BAD & 01 \\
\hline Bibliomar & 01 \\
\hline Informação \& Sociedade: Estudos & 01 \\
\hline Documentação & 01 \\
\hline Revista de Ciência da Informação e & 01 \\
\hline Revista BIBLOS & 01 \\
\hline Revista Fontes Documentais & 01 \\
\hline Táginas a \& b - arquivos \& bibliotecas & 01 \\
\hline Riência - Revista da Rede de Ensino FTC & 01 \\
\hline RevioCanto & 17 \\
\hline
\end{tabular}

Fonte: elaborado pela autora (2020).

Percebe-se na Tabela 2 que ao menos 15 revistas científicas publicaram artigos que abordam o MAA e os repositórios institucionais, neste caso específico, o RI-UFBA.

Ao partirmos para a análise dos anos de publicação desses artigos, observamos que um artigo foi publicado em 2010 e em 2011, enquanto em 2012 foram publicados dois artigos. Em 2013 e 2014 novamente somente um artigo foi publicado com essa temática em cada ano. Em 2015, voltamos a ter dois artigos publicados sobre o repositório da UFBA. Em 2016 somente um artigo foi publicado e em 2017 identificamos mais dois artigos publicados. Em 2018 não houve artigo publicado em revista científica sobre o RI-UFBA. Em 2019 obtivemos mais dois artigos disponibilizados ao público entusiasta sobre o assunto, todavia o ano de 2020, em que se comemora uma década de criação do RI-UFBA, observa-se a publicação de 
quatro artigos em periódico científico, o que demonstra um crescimento expressivo sobre a temática e acerca do repositório institucional da UFBA em particular.

No Gráfico 1 apesenta-se a evolução de artigos sobre o RI-UFBA publicados em periódicos científicos entre os anos de 2010 e 2020.

Gráfico 1: Artigos em periódicos científicos sobre o RI-UFBA

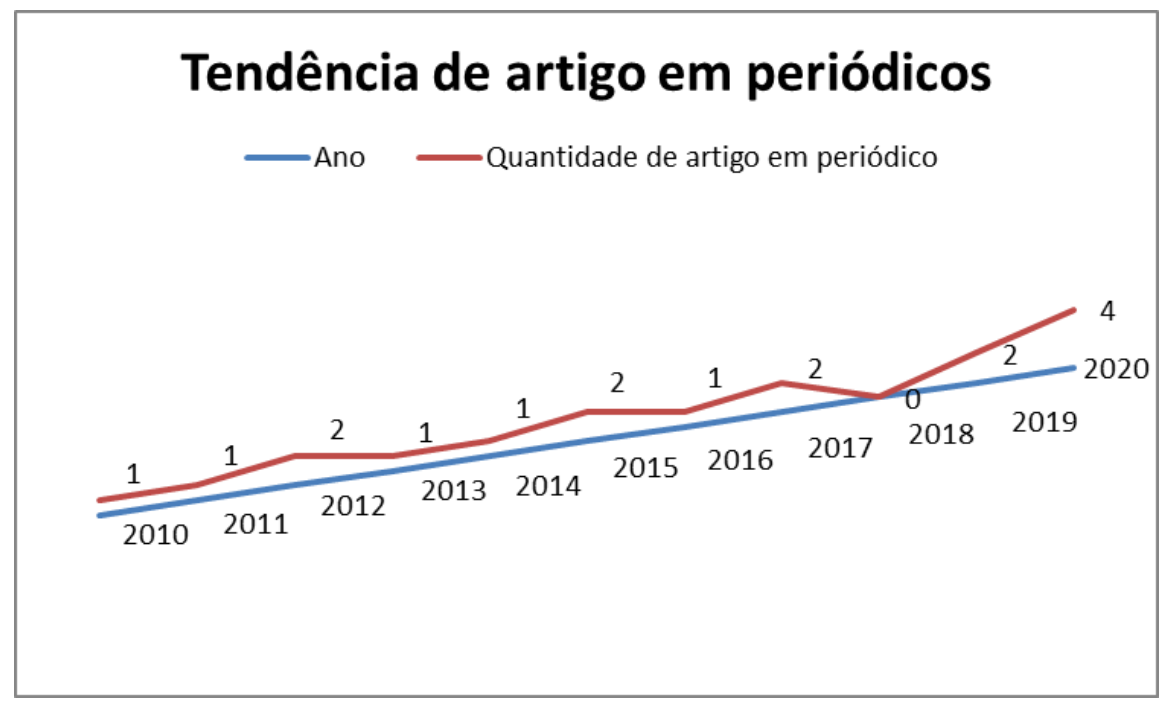

Fonte: elaborado pela autora (2020).

O Gráfico 1 exibe de forma clara e eficiente a quantidade de artigos publicado por ano, no que compete a temática do repositório institucional da UFBA. Percebe-se uma oscilação entre os anos no tange o quantitativo de textos publicados. Por um lado, temos alguns anos com apenas um artigo em periódico, como observado em 2010, 2011, 2013, 2014 e 2016. Por outro lado, o ano de 2018 não apresentou nenhum artigo publicado sobre o RI-UFBA em periódico. Nos anos de 2012, 2015, 2017 e 2019 foram publicados dois artigos por ano em revista científica, contudo o ano de destaque em termos de quantidade de artigos publicados em periódicos sobre a temática foi em 2020, com quatro artigos produzidos e publicados em periódicos de acesso aberto, sobre o RI-UFBA.

Feita a análise detalhada sobre as publicações de artigos em periódicos, voltemo-nos aos trabalhos apresentados em eventos, que reuniu 11 trabalhos, distribuídos entre eventos nacionais e internacionais, realizados no estado da Bahia ou mesmo fora do estado e do País.

No Tabela 3 apresentamos os eventos que publicaram sobre o RI-UFBA, assim como, o local de realização do evento. 
Tabela 3: Eventos com artigos publicados sobre o RI-UFBA

\begin{tabular}{|c|c|c|c|}
\hline Evento & Local & Ano & Artigos \\
\hline $\begin{array}{l}4^{\circ} \text { Simpósio de Avaliação da } \\
\text { Educação Superior }\end{array}$ & Salvador & 2019 & 01 \\
\hline $\begin{array}{l}\text { IX Conferência Internacional } \\
\text { sobre Bibliotecas e } \\
\text { Repositórios Digitais da } \\
\text { América Latina (BIREDIAL- } \\
\text { ISTEC'19) - BRASIL }\end{array}$ & São Paulo & 2019 & 01 \\
\hline $\begin{array}{c}\text { XX Seminário Nacional de } \\
\text { Bibliotecas Universitárias - } \\
\text { SNBU }\end{array}$ & Salvador & 2018 & 02 \\
\hline $\begin{array}{c}\text { XXVII congresso Brasileiro de } \\
\text { Biblioteconomia, Documentação } \\
\text { e Ciência Da Informação - } \\
\text { CBBD }\end{array}$ & Fortaleza & 2017 & 01 \\
\hline $\begin{array}{l}\text { XVIII Encontro Nacional de } \\
\text { Pesquisa em Ciência da } \\
\text { Informação - ENANCIB }\end{array}$ & Marília - SP & 2017 & 01 \\
\hline $\begin{array}{l}7^{\mathrm{a}} \text { Conferência Luso-Brasileira } \\
\text { sobre Acesso Aberto - Confoa }\end{array}$ & $\begin{array}{l}\text { Instituto Politécnico de } \\
\text { Viseu, Portugal. }\end{array}$ & 2016 & 01 \\
\hline $\begin{array}{l}10^{\circ} \text { Encontro Nacional de } \\
\text { História da Mídia }\end{array}$ & Porto Alegre & 2015 & 01 \\
\hline $\begin{array}{l}3^{\mathrm{a}} \text { Conferência Luso-Brasileira } \\
\text { sobre Acesso Aberto - Confoa }\end{array}$ & $\begin{array}{c}\text { Universidade Nova de } \\
\text { Lisboa }\end{array}$ & 2013 & 01 \\
\hline $\begin{array}{c}\text { I Semiário do Conheciemento, } \\
\text { Invovação e Comunicação em } \\
\text { Serviços de Saúde } \\
\end{array}$ & Salvador & 2013 & 01 \\
\hline $\begin{array}{c}\text { V ENECULT - Encontro de } \\
\text { Estudos Multidisciplinares em } \\
\text { Cultura }\end{array}$ & Salvador & 2009 & 01 \\
\hline
\end{tabular}

Fonte: elaborado pela autora (2020).

Observa-se na Tabela 3 que o tema repositório institucional da UFBA foi comunicado em dez eventos diferentes entre os anos de 2009, antes mesmo da sua implantação oficial, até o ano de 2019. Desses dez eventos, evidencia-se que o XX SNBU que ocorreu em Salvador, em 2018, contou com duas apresentações de trabalho a respeito do tema, os demais eventos apresentaram apenas um trabalho com essa temática. Outro dado a salientar é que ente os anos 
de 2010 e 2012 não identificamos comunicações orais e eventos que abordassem o tema do repositório da UFBA.

Quanto à autoria, destacamos que os autores com mais publicações acerca dessa temática são: Flávia Rosa, autora que desencadeou a implantação do RI-UFBA através dos seus estudos relacionados à tese intitulada $A$ disseminação da produção científica da Universidade Federal da Bahia através da implantação do seu repositório institucional: uma política de acesso aberto, defendida em 2011 no Programa Multidisciplinar de PósGraduação em Cultura e Sociedade, da Universidade Federal da Bahia. Em alguns dos artigos publicados em periódicos ou apresentados em eventos, a autora conta com o suporte de outros autores, que trilham o mesmo caminho rumo aos estudos sobre o MAA e suas estratégias de comunicação científica em acesso aberto, seja na via verde e/ou na via dourada.

Outros autores de destaque são Rodrigo Meirelles, que participou ativamente da implantação do RI-UFBA, inclusive como consultor técnico junto ao Ibict, apoiando a parte tecnológica da implantação, assim como atuando como coordenador por ocasião do povoamento do repositório (ROSA, 2011). Outra autora que merece ser destacada é Susane Barros, que têm atuado junto à Flávia Rosa nas pesquisas sobre o RI-UFBA, com diversos artigos publicados em coautoria entre essas pesquisadoras.

\subsection{Perspectivas de crescimento do RI-UFBA}

Ao analisarmos os dados apresentados no tópico anterior, podemos evidenciar que o RIUFBA tem sido agraciado com diversos estudos. O quantitativo de 44 documentos recuperados que versam sobre o repositório da UFBA, de alguma forma mantém ativa a perspectiva de investigação acerca desse importante instrumento de comunicação científica, que visa, além de comunicar as produções acadêmicas e científicas da instituição, possui a prerrogativa da preservação e memória.

As opções de investigação sobre o RI-UFBA são inúmeras, seja qual for o viés escolhido, este acolherá os pesquisadores com uma ampla quantidade de documentos, de diferentes tipologias e fontes de informação. Estudos promissores perpassam também pela análise da inserção de documentos pelos discentes de graduação, assim como pelos materiais 
acadêmicos, pois como acrescenta Rosa (2011), um dos objetivos da construção e implantação de um instrumento que possibilitasse o acesso aberto, era justamente minimizar o uso de pastas em copiadoras da Universidade, tenho o RI como esse instrumento para socialização dos materiais utilizados em sala de aula, assim como a troca acadêmica e científica entre discentes e docentes.

Além de ter como objetivo homenagear o RI-UFBA pelos seus dez anos de implantação, assim como mapear os documentos que já foram escritos sobre esse instrumento de comunicação científica, cabe-nos despertar o interesse de outros pesquisadores a realizar investigações que compreendam os variados temas implícitos no repositório. Nesse sentido, uma oportunidade de crescimento para o RI-UFBA pode ter os Programas de Pós-|Graduação (PPG) como parceiros, visto que, por meio desses, diversos documentos são produzindo, seja em virtude das defesas de dissertações e teses realizadas pelos discentes, seja pela produção científica dos docentes, que publicam ou deveriam publicar em revistas científicas, em anais de congressos, capítulos de livros, assim como documentos administrativos, como regimentos internos, editais de processos seletivos, de concessão de bolsas, de projetos de pesquisas submetidos às agências de fomento, entre outros. São inúmeras as opções de documentos que podem constituir o acervo da comunidade acadêmica de cada unidade de ensino.

Estudos realizados por Santos e Rosa (2020) revelaram que alguns PPG da área de Ciências Exatas, objeto da sua investigação, não estão disponibilizando adequadamente as dissertações e teses aprovadas. Alguns PPGs inclusive disponibilizam na homepage do programa, mas não inseriram no RI-UFBA, que atua como um potencializador da visualização dessas teses e dissertações, visto que atua com metadados que podem ser recuperados através do site de busca Google. Atuar junto a esses PPG, de modo que possam compreender a importância da inserção das produções acadêmicas no RI-UFBA é um amplo campo de debates e articulações.

\section{CONSIDERAÇÕES FINAIS}

Considerando que um dos elementos que traduz a importância do RI-UFBA seja o quantitativo de documentos recuperados sobre ele, seja como objeto de pesquisa ou de referência, concluímos que o repositório tem atuado de forma significativa no cotidiano das 
comunidades acadêmicas da UFBA e fora dela, visto que pesquisadores de outras instituições também o tem mencionado em seus estudos. Os documentos que fizeram parte desse mapeamento revelam que o repositório tem sido analisado com uma frequência satisfatória, ficando um ou outro ano sem maiores publicações e menções ao seu potencial.

Percebe-se que estudos mais voltados à sua divulgação por parte das instâncias superiores ainda são insuficientes. As comunidades acadêmicas necessitam de um suporte que permita a internalização por parte dos seus membros acerca dos benefícios que a adoção ao acesso aberto, através do RI-UFBA, pode trazer aos pesquisadores, ao terem os seus estudos publicados de forma ampla e irrestrita, podendo atingir um grau de citações relevante.

Os PPGs por sua vez, devem incentivar os seus membros, sejam discentes ou docentes, para a disponibilização de suas dissertações, teses, artigos publicados em revistas, respeitando as políticas de arquivamento e os períodos de embargo, quando houver. Trabalhos publicados em eventos, quando publicados em anais, podem fazer parte do acervo do RI-UFBA, visto que não adotam períodos de embargo como os periódicos científicos. Capítulos de livros, relatórios de pesquisa e tantas outras produções acadêmicas dos PPG também devem compor o repositório, sempre que possível. Vida permanente para o RI-UFBA e que a cada ano e cada vez mais os pesquisadores assumam o compromisso com a sua instituição ao disponibilizar a sua produção, seja ela textual, seja em imagem, imagem em movimento, som e diversos outros formatos.

Esse trabalho buscou homenagear o Repositório Institucional da UFBA em seus dez anos de existência, visando demonstrar a amplitude que a ferramenta adquiriu ao longo dessa primeira década, fortalecendo e incentivando a comunicação científica em acesso aberto, assim como contribuindo para alavancar as pesquisas científicas desenvolvidas no âmbito da Universidade Federal da Bahia. O RI-UFBA se apresenta como um objeto de estudo com diversas perspectivas de investigação científica, o que possibilita o desenvolvimento de futuras pesquisas acerca da comunicação científica e da disponibilização de conteúdo acadêmico e científico em acesso aberto.

\section{REFERÊNCIAS}

ALVAREZ, Gonzalo Rubén; CAREGNATO, Sônia Elisa. Preprints na comunicação científica da física de altas energias: análise das submissões no repositório arxiv (2010-2015): 
análise das submissões no repositório arXiv (2010-2015). Perspectivas em Ciência da Informação, Belo Horizonte, v. 22, n. 2, 2017. Disponível em: https://www.scielo.br/pdf/pci/v22n2/1981-5344-pci-22-02-00104.pdf. Acesso em: 30 abr. 2020.

COSTA, Elaine Hipólito dos Santos. Periódicos de acesso aberto: um canal de disseminação dos pesquisadores bolsistas pq1a do cnpq?. 2018. Tese (Doutorado em Ciência da Informação) - Escola de Comunicação, Universidade Federal do Rio de Janeiro, Rio de Janeiro, 2018. Disponível em:

https://ridi.ibict.br/bitstream/123456789/977/1/Elaine_teseCompleta_POS_DEFESA_FINALI ZADA_14_09_2018.pdf. Acesso em: 02 maio 2020.

COSTA, Michelli Pereira da; LEITE, Fernando César Lima. Acesso Aberto no mundo e na América Latina: uma revisão a partir da BOAI. TransInformação, Campinas, v. 28, n. 1, p. 33-46. jan./abr. 2016. Disponível em:

http://repositorio.unb.br/bitstream/10482/19433/2/AcessoAbertoMundo_\%202016.pdf. Acesso em: 29 abr. 2020.

CUNHA, Murilo Bastos da. Manual de fontes de informação. 2. ed. Brasília, DF: Briquet de Lemos, 2020.

FONSECA, João José Saraiva. Metodologia da pesquisa científica. Fortaleza: UEC, 2002. Apostila. Disponível em: http://www.ia.ufrrj.br/ppgea/conteudo/conteudo-20121/1SF/Sandra/apostilaMetodologia.pdf. Acesso em: 17 set. 2019.

GIL, Antonio Carlos. Métodos e técnicas de pesquisa social. 6. ed. São Paulo: Editora Atlas, 2008

KURAMOTO, Hélio. A informação científica e o seu acesso livre: que direção o Brasil está adotando?: que direção o Brasil está adotando?. Bibliotecas Universitárias: pesquisas, experiências e perspectivas, Belo Horizonte, v. 2, n. 1, p. 6-28, fev. 2015. Disponível em: https://www.brapci.inf.br/index.php/article/download/53017. Acesso em: 30 abr. 2020.

KURAMOTO, H. Nova oportunidade para construção de seu repositório. Blog do Kuramoto, [s. l.], 2009. Disponível em: https://kuramoto.wordpress.com/2009/12/11/nova-oportunidadepara-construcao-de-seu-repoositorio/. Acesso em: 30 abr. 2020.

MEADOWS, A. J. A comunicação científica. Brasília, DF: Briquet de Lemos, 1999.

MEIRELLES, Rodrigo França. Gestão do processo editorial eletrônico, baseado no modelo acesso aberto: estudo em periódicos científicos da Universidade Federal da Bahia UFBA. 2009. Dissertação (Mestrado em Ciência da Informação) - Instituto de Ciência da Informação, Universidade Federal da Bahia, Salvador, 2009. Disponível em: https://repositorio.ufba.br/ri/bitstream/ri/5629/1/Disserta\%C3\%A7\%C3\%A3o_Rodrigo_Mei relles_Revisada.pdf. Acesso em: 30 abr. 2020. 
MINAYO, Maria Cecília de Souza (org.). Pesquisa social: teoria, método e criatividade. Petrópolis: Vozes, 1992.

ROSA, Flávia Goulart Mota Garcia. A Disseminação da produção científica da Universidade Federal da Bahia através da implantação do seu Repositório Institucional: uma política de acesso aberto. Salvador, 2011. Tese (Doutorado em Cultura e Sociedade) Faculdade de Comunicação, Universidade Federal da Bahia, Salvador, 2011. Disponível em: https://repositorio.ufba.br/ri/bitstream/ri/3031/1/Tese\%20Flavia.pdf. Acesso em: 30 abr. 2020.

SANTOS, Davilene Souza; ROSA, Flávia Goulart Mota Garcia. Repositório Institucional da UFBA: visibilidade das produções acadêmicas dos graduados

Revista BiblioCanto, Natal, v. 6, n. 1, p. 40-60, 2020. Disponível em:

https://periodicos.ufrn.br/bibliocanto/article/view/21356/13691. Acesso em: 31 out. 2020.

SILVA, Terezinha Elisabeth; ALCARÁ, Adriana Rosecler. Acesso aberto à informação científica: políticas e iniciativas governamentais. Informação e Informação, Londrina, v. 14, n. 2, p. 100-116, jul./dez. 2009. Disponível em:

http://www.uel.br/revistas/uel/index.php/informacao/article/view/4817/4173. Acesso em: 29 abr. 2020.

TARGINO, Maria das Graças. Comunicação científica: o artigo de periódico nas atividades de ensino e pesquisa do docente universitário brasileiro na pós-graduação. 1998. Tese (Doutorado em Ciência da Informação) - Faculdade de Estudo Sociais Aplicados, Universidade de Brasília, Brasília, DF, 1998. Disponível em: http://repositorio.unb.br/handle/10482/34362. Acesso em: 29 abr. 2020.

TRISKA, Ricardo; CAFÉ, Lígia. Arquivos abertos: subprojeto da Biblioteca Digital Brasileira. Ciência da Informação, Brasília, v. 30, n. 3, p. 92-96, set./dez. 2001. Disponível em: http://www.scielo.br/scielo.php?script=sci_arttext\&pid=S0100-19652001000300012. Acesso em: 29 abr. 2020.

UNIVERSIDADE FEDERAL DA BAHIA. Gabinete do Reitor. Portaria n⿳0 024/2010. Salvador: Palácio da Reitoria, 2010. Disponível em: https://repositorio.ufba.br/ri/about/politica\%20institucional.pdf. Acesso em: 29 abr. 2020.

UNIVERSIDADE FEDERAL DA BAHIA. Gabinete do Reitor. Portaria n⿳ 125/2015. Salvador: Palácio da Reitoria, 2015. Disponível em: https://repositorio.ufba.br/ri/about/Portaria_n125.pdf. Acesso em: 29 abr. 2020. 